\title{
Social RE-PBL: An Approach for Teaching Requirements Engineering Using PBL, SNSs, and Cloud Storages and File-Sharing Services
}

\author{
Lamis F. Al-Qora'n
}

\begin{abstract}
Requirements engineering process showed that it has the potential to affect software development process and consequently cause unexpected problems in the produced software. Reducing the likelihood of such issues requires proper preparation for software engineering students during their undergraduate studies to reduce the gap between theory and practice. Students must develop the soft skills that are needed to practice software engineering activities, especially requirements engineering. Accordingly, encouraging students to learn and practice requirements engineering concepts and activities are required. Students undertake the requirements engineering course in one semester, where the lecturer focuses on delivering the theoretical concepts to students which creates teacher-centred learning. It is difficult for students to develop the required critical thinking and communication skills that enable them to solve real-world problems in such a teacher-centred environment. This study uses Project-Based Learning (PBL), Social Networking Sites (SNSs) and cloud enhanced communication to design a non-traditional teaching approach to improve students' learning and to achieve a learner-centred learning environment in a requirements engineering course. The developed approach was applied to a requirements engineering course at our university to investigate its effectiveness and its impact on students' learning ability. The students in the investigational group learned with the new method; however, the students in the control group learned with the traditional learning method. The results of our experiment show that the proposed approach significantly improved the achievement, motivation and attitude of our students as well as their ability to approach and solve real-world problems.
\end{abstract}

Index Terms-Project-based learning, RE education, social networks sites (SNSs) for education, teaching requirements engineering.

\section{INTRODUCTION}

A specific problem related to teaching software engineering courses is related to teaching requirements engineering. In Jordan, teaching and learning Requirements Engineering (RE) is a principal subject for a four-year course to get the Undergraduate Degree in Software Engineering. According to the program, students generally undertake a complete requirements engineering module. After finishing the module, students are expected to be able to: select and use

Manuscript received September 12, 2020; revised March 23, 2021. This work was supported by the Deanship of Scientific Research at Philadelphia University.

Lamis F. Al-Qora'n is with the Software Engineering Department, Philadelphia University, Jordan (e-mail: lalqoran@ philadelphia.edu.jo). proper elicitation techniques according to the problem to be solved, evaluate and analyse the elicited requirements, document the requirements and validate the Software Requirements Specification (SRS).

After teaching the course for university students in the Department of Software Engineering at Philadelphia University/ Jordan, we specified some of the problems related to teaching the course. Moreover, we have noticed that students' performance in graduation projects does not match the efforts that are done during the requirements engineering course, which indicates that a problem is being there. For further investigation of the problem sixteen interviews were conducted with students undertaking the course and lecturers in the department.

We have refined the topics of requirements engineering module over the last five semesters based on the feedback received from our students, from the internal examiner and the supervisor of the graduation projects in our department. We found that the problem is with the teaching approach that is in use and we recognized that new creative approaches for teaching are required.

In this paper, we propose the Social RE-PBL approach which we have tested in our department. To examine its usefulness, we provide a direct comparison between a class that was taught using traditional classroom education (both lectures and tutorials) and a class that was taught using the Social RE-PBL creative approach. The Social RE-PBL approach applies Project-Based Learning (PBL) and combines it with the use of Social Networking Sites (SSNs) (mainly, Facebook Messenger groups), the File Storage Service (Google Drive) and the File Syncing service (Google Docs).

Students seem to have a better understanding of the concepts in class after sharing and exchanging ideas. Our teaching philosophy is based on real-time interactive learning using SSNs. This interaction has the potential to help in improving students' performance in practice -as students are motivated to use social networks- and to help students to realize and better understand the concepts that are learned during the course. The remainder of the paper explains the research design, the proposed approach and our results in detail.

\section{RELATED WORK}

\section{A. Teaching Requirements Engineering Background}

The requirements Engineering process is an essential part of the software development process. It is a spiral process 
that has a set of activities which need to be fulfilled. RE is concerned with real-world goals of software systems, their functions, constraints and the relationship of these factors and their effect on the correct specification of software evolution and behaviour over time [1].

Software development research has found that requirements activities that are undertaken are the leading causes of failures and deficiencies of software systems and deviations or elimination of any of these activities contribute to producing a software product that does not satisfy stakeholders' needs [2].

The lack of skills and knowledge of the software engineers who are responsible for the RE process have a direct impact on such failures and deficiencies [3]. Proper teaching of RE at the university level has a key impact on building the required skills for this occupation [4].

\section{B. Project-Based Learning (PBL)}

PBL assumes that students require opportunities to build up knowledge through real-world problem solving where students ask and refine questions, formulate and conduct research, collect, investigate and analyse data to conclude and document results [5]. Furthermore, students develop knowledge and understanding of the concepts while inspecting and investigating a problem by searching different resources and benefiting from their teachers' guidance and instructions [6].

Technical knowledge is crucial for the software development process, however, communication skills, working in a group, assigning tasks and monitoring the work progress as well as taking responsibility for making choices are required skills for the software development process [7]. There are lots of defenders of students' engagement in solving real-world problems that involve real stakeholders through project work [8]-[10].

In this paper we are supporters for such engagement, thus we provide a teaching approach that focuses on interactive social learning through projects that involve direct interaction with real stakeholders instead of simulated stakeholders. Such an approach helps students to develop the required skills and to help them to approach real projects in the future.

\section{The Use of Social Networks Sites (SNSs), Cloud storages Services and File-Sharing Services in Education}

Social networks are public, internet-accessed, cloud-based, social interaction environments that have the potential to change the way people interact with each other [11]. They are commonly used by users for communication and interaction; however, many researchers believed that they can be used as educational tools which have a positive impact on learning [12]-[14]. For example, Facebook is a social network that is used for educational purposes as an educational tool [15]-[17]. In their study [18] confirmed former results in the literature in regard to the usefulness of Facebook (a Social networking site) for learning; that Facebook provides key approaches for learning and it is useful for effective communication between peers. Moreover, C. Lampe et al. [19] investigated how do students perceive using Facebook for classroom-related collaborative activities and found that using social media tools improved students' self-efficacy and create students who are motivated to communicate with others.

N. Madhav et al. [20] stated that using cloud enhanced communication amongst peers and lecturer has the potential to help with their project and assignment submissions. Furthermore, Y. Huang [21] studied the intention of students to use Google Docs and Google Slides as collaborative learning tools and found it to be positive.

L. Qin et al. [22] examined the efficiency of using Google Drive and its relationship with the performance of team members', they identified that computer self-efficacy and the quality of teamwork have a key effect on the application of cloud-based collaboration services amongst team members.

This study makes use of Social Networks (Facebook Messenger groups), File Storage Service (Google Drive) and the File Syncing Service (Google Docs) to develop an approach to teaching RE.

\section{RESEARCH DESIGN}

For this study we built a 4-phase research method; Phase 1: study the need for a new approach to focus on solving real-world problems in the learning environment for undergraduate students at the department of software engineering, Philadelphia University, Phase 2: develop and test the Social RE-PBL approach emphasizing on cognitive-communication skills in the learning environment for undergraduate students at the department of software engineering, Philadelphia University, Phase 3: examine the use of Social RE-PBL approach in the learning environment for undergraduate students at the Department of Software Engineering, Philadelphia University, and Phase 4: evaluate the Social RE-PBL in the learning environment for undergraduate students at Department of Software Engineering, Philadelphia University.

In Phase 1, we have investigated the need for an interactive approach that focuses on cognitive-communication skills in the learning environment for undergraduate students at the department of SE, Philadelphia University. To accomplish our investigation, we have conducted eleven interviews with students who finished the course with the traditional teaching method. We tried to identify the needs from the target learners and to find out the difficulties they have faced in understanding the basic concepts of requirements engineering. Four students from this group have already graduated and are working in different companies. The other seven students have finished the course and they are undertaken the next course in their study plan which is "Software Architecture" module. Then, we conducted four interviews with four lecturers (one of them is the supervisor for graduation projects) to find the challenges, problems and to know the opportunities. Our solution is based on the analysis of students', lecturers and stakeholders needs. Moreover, one interview was conducted with a Senior Manager in Software Development.

After analysing the content of our interviews, we could organize the information into challenges and opportunities. Details of the themes are described in Table I. 
TABLE I: ANALYSIS OF THE INTERVIEWS

\begin{tabular}{|c|c|c|}
\hline & $\begin{array}{l}\text { Problems and } \\
\text { Challenges }\end{array}$ & Opportunities \\
\hline \multirow{8}{*}{$\begin{array}{l}\text { Graduated } \\
\text { Students } \\
\text { Working in } \\
\text { Companies }\end{array}$} & way & Application \\
\hline & communication and a & knowledge via real \\
\hline & language that can be & projects \\
\hline & understood by all & \\
\hline & parties. & Training and practice in \\
\hline & Distressed start & real-working \\
\hline & because this is the first & environment \\
\hline & real-world project & \\
\hline
\end{tabular}

There is no enough Training and practice in time to give students a real-working

Lecturers the opportunity to environment practice what they are Engagement of learning students in real-world Dealing with real problems and stakeholders is collaboration between difficult because of learners, educators, and their time stakeholders.

Sharing the elicited requirements with stakeholders and educators at the same time (distributing the requirements to educators and to different stakeholders).

\begin{tabular}{llll}
\hline Senior & Lack of confidence & Engagement \\
Manager in & when approaching & of \\
Software & their first real-world in real-world & problems \\
Development & project. & collaboration between \\
& Lack & of learners, educators, and \\
& communication skills & stakeholders. \\
& and problems with & \\
& understanding & \\
& stakeholders' needs. & \\
&
\end{tabular}

In phase 2 a Social RE-PBL approach was designed and reviewed many times, Fig. 1 depicts the approach. To address all the challenges and to invest the opportunities we established the Social RE-PBL framework as shown in Fig. 2 Interactive learning can be achieved through collaborative working groups and learning from reflection on students' learning experiences.

As shown above, Students are expected to practice the activities of the RE process during the semester. Traditional lectures are delivered to students who start building up their groups from the first week in the semester and who have to prepare their projects' proposals which have to be shared through a Facebook Messenger group (which is created for the purpose of communication between registered students and the lecturer) and have to be approved by the lecturer.

Students have to apply the RE process that they learn in class on their projects and have to share their artifacts on Google Drive with both stakeholders and lecturer who give their feedback and comments and, in most cases, introduce some modifications. Students' work has to be supervised by the lecturer through the sharing services to make sure that students are not left and that they are working toward achieving their specified goals.

The following (Table II) are the deliverables that are expected to be submitted by each group and the deadline for the submission through the semester.

In Phase 3, the model was applied and examined. Students were asked to make groups for conducting a real-world project for each group. Students in each group are asked to share their ideas through the Facebook Messenger group, and they were asked to apply each step that is explained in the class to their project which must include direct interaction with stakeholders. As mentioned previously, students were asked to share their artefacts on Google Drive with stakeholders and with the lecturer to receive the lecturers' and stakeholders' feedback, comments and modifications.

Students' work was supervised by the lecturer through the sharing services who make sure that students are not left. In addition to monitoring the groups, the lecturer was responsible for monitoring the team meetings.

TABLE II: PROJECT DELIVERABLES

\begin{tabular}{|c|c|c|c|}
\hline Deliverables & Deadline & Scope & Shared with \\
\hline $\begin{array}{l}\text { Project } \\
\text { proposal }\end{array}$ & $\begin{array}{l}\text { End of } \\
\text { week } 1\end{array}$ & Team & Lecturer \\
\hline $\begin{array}{l}\text { Elicited } \\
\text { Requirements }\end{array}$ & $\begin{array}{l}\text { End of } \\
\text { week } 6\end{array}$ & Individual & $\begin{array}{l}\text { Lecturer and } \\
\text { Stakeholders }\end{array}$ \\
\hline $\begin{array}{l}\text { Evaluated } \\
\text { Requirements }\end{array}$ & $\begin{array}{l}\text { End of } \\
\text { week } 9\end{array}$ & $\begin{array}{l}\text { Consistency and } \\
\text { risk Analysis are } \\
\text { supervised by the } \\
\text { lecturer } \\
\text { (Collaborative team } \\
\text { work) } \\
\text { Prioritisation and } \\
\text { Comparison } \\
\text { between } \\
\text { Alternatives } \\
\text { (team and } \\
\text { stakeholders) }\end{array}$ & Lecturer \\
\hline$\overline{\text { Draft SRS }}$ & $\begin{array}{l}\text { End of } \\
\text { week } 13\end{array}$ & $\begin{array}{l}\text { Work is shared on } \\
\text { Google Docs- team) }\end{array}$ & $\begin{array}{l}\text { Lecturer and } \\
\text { Stakeholders }\end{array}$ \\
\hline Validation & $\begin{array}{l}\text { End of } \\
\text { week } 15\end{array}$ & Team work & $\begin{array}{l}\text { Lecturer and } \\
\text { stakeholders }\end{array}$ \\
\hline Final SRS & $\begin{array}{l}\text { Beginning } \\
\text { of week } 16\end{array}$ & Team & $\begin{array}{l}\text { Lecturer and } \\
\text { stakeholders }\end{array}$ \\
\hline
\end{tabular}

Students' work was then assessed where student's marks were given on the individual assignments (20\%) and team deliverables (80\%). Deliverables, as demonstrated in Table II, included elicitation documents such as interviews transcripts, 
prioritisation of requirements and SRS. Marks were also given on both group and individual presentations. Team members may contribute differently, so each team member was asked to rate their colleagues' work and to give a percentage that represents each student's contribution to the team effort. Moreover, when submitting deliverables students were asked to submit the contribution percentage for each member and a reflection report to help in the assessment process.

Thus, the approach is based on developing proper assessment tasks as well as creating appropriate assessment methods and tools. Then students' results are implemented and analysed. Finally, students' final marks are calculated from the previous assessments.

In phase 4, the approach was evaluated by the lecturer and a questionnaire was distributed to students for evaluation purposes. Details on the evaluation process come in the next section.

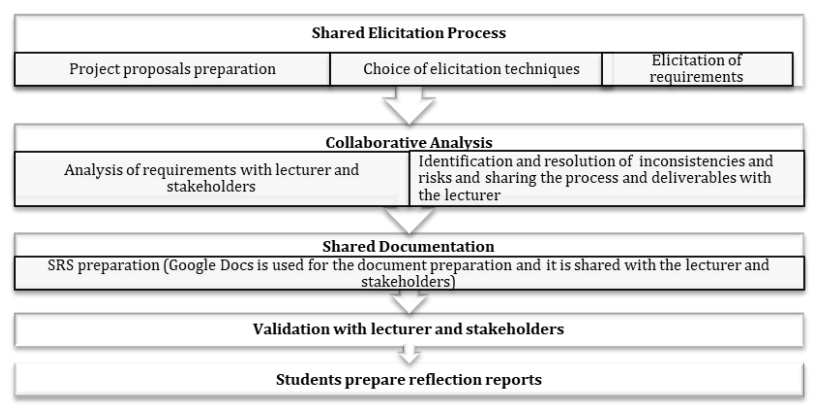

Fig. 1. Social RE-PBL approach.

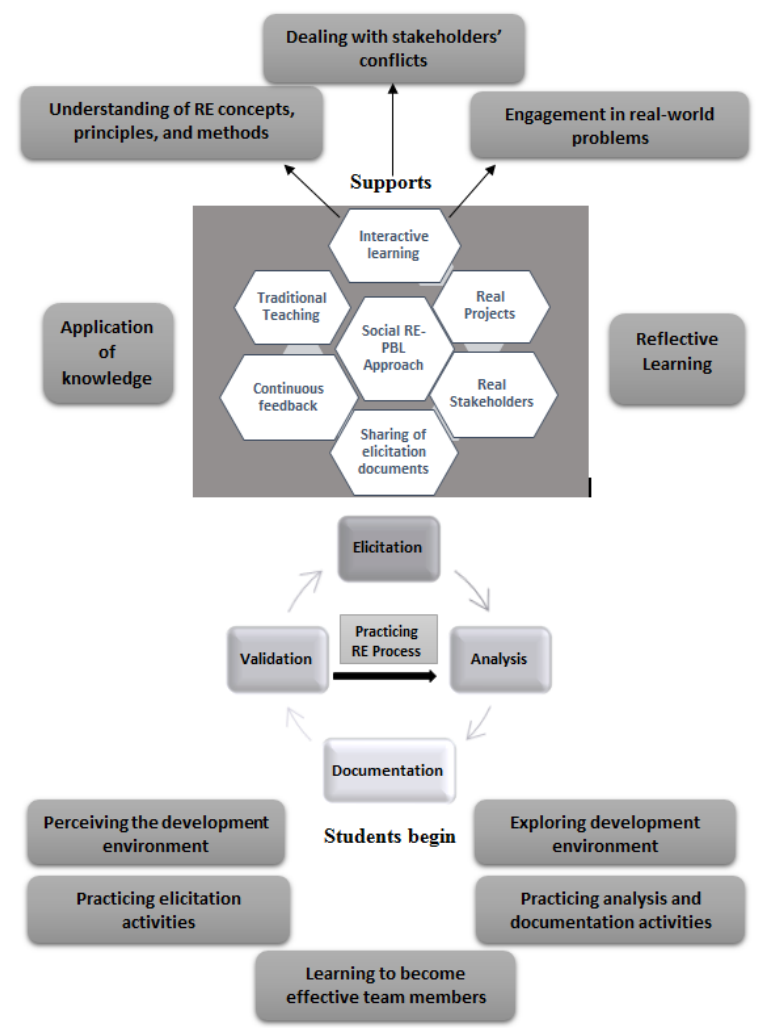

Fig. 2. Social RE-PBL framework.

\section{EVAlUAtion OF SOCIAL RE-PBL APPROACH}

\section{A. Evaluation of Students' Results}

The aim of this study is to collect information that would help us to assess and improve the requirements engineering teaching process. At the same time, the study targeted assessing the relationship between improving the requirements engineering teaching process and students' performance. Therefore, students' Grades and assessment results are analyzed. Lecturers are most likely to rely on students' grades in exams and other assessments to measure whether the completed course met its proposed objectives and learning outcomes. Moreover, students' demonstration of competency in learning outcomes and their feedback on the course can be used to judge the success of the course.

The effectiveness of the approach that is proposed to achieve such improvement is tested on the requirements engineering course, where two groups of students were selected:

1) The control group which has 18 students (Group A): The 2017 intake students who took the requirements engineering course in September 2018 (learned with the traditional learning method).

2) Investigational group which has 16 students (Group B): The 2018 intake students who took the requirements engineering course in September 2019 (learned with the new approach).

Students in Group B achieved better results and their marks were away better than students in Group A. They also showed a better understanding of the concepts and demonstrated the ability to work in a team and to be an effective team member. When compared to the students in Group A, students in Group B developed better communication skills through experiencing real projects and through enhanced students' engagement levels.

Students in the investigational group also showed that they can keep learning from the project through guided reflections. This could be beneficial for lecturers as well where they can pick up and assess students' accomplishments and projects from students' e-portfolios.

Moreover, the proposed approach proved that it could provide a strategy that helps students to achieve long-term archiving of their work. The primary role is that they also can use those artefacts for supporting and connecting the learning across courses by using such artefacts to complete their projects in other modules such as the Software Architecture module.

\section{B. Evaluation Using Five-Point Likert Scaling}

Students in the two groups received a feedback survey to know their thoughts about the Social RE-PBL approach. Each item in the survey was quantified by a Likert-scale of 1 to $5(1=$ Very Poor $[\mathrm{VP}], 2=$ Poor $[\mathrm{P}], 3=$ Fair $[\mathrm{F}], 4=$ Good [G], $5=$ Excellent [E]). Simply, we can use Likert scaling to measure students' attitude toward engineering and technology [23]. This method is accepted because constructing and modifying this kind of scaling is easy and it has proved good reliability through collecting and analyzing an extensive quantity of data with less effort and time [24]. The results in Fig. 3 below showed that after teaching with traditional approach students showed poor understanding of the terms and concepts as well as of the RE activities where $78 \%$ (14 out of 18) evaluated their understanding of the concepts, terms and activities as poor. On the other hand, 
students who were taught using Social RE-PBL showed better understanding where $88 \%$ (14 out of 16) of students in Group B answered that they have excellent understanding of the concepts, terms and activities. This demonstrated the ability of Social RE-PBL to improve students' understanding.

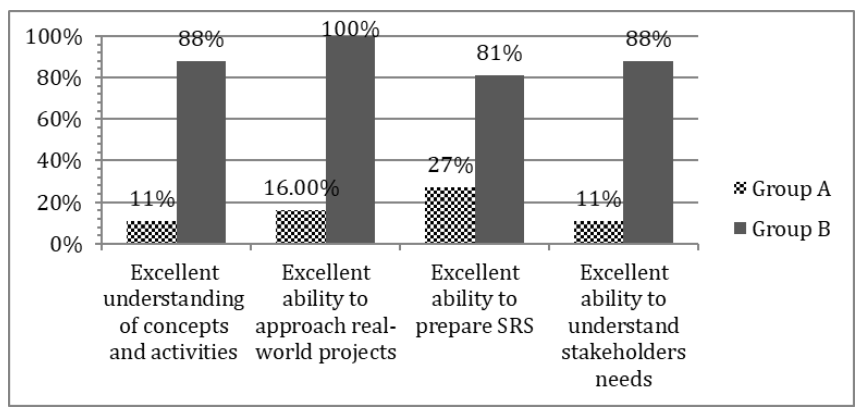

Fig. 3. Five-point Likert scaling results.

\section{LIMITATIONS}

\section{A. Limitations of the Study}

The first limitation of our research is that the sample size could be bigger so that we can get more trusted results. Students' evaluation of the used approach maybe subjective and could be affected by their results in the course. Therefore, we distributed the survey to students before seeing their final grades.

\section{B. Limitations of the Social RE-PBL}

Lecturers showed negative impression toward the effort and the use of the tools that are required for the assessment process. Moreover, they had concerns regarding to the frequency with which assessment data are shared. Here, we specified the need for sharing our research results with the lecturers in the department to show its effectiveness. Moreover, we considered studying the factors that can contribute positively to the adoption of such teaching and learning methodologies by lecturers.

On the other hand, students who learned using Social RE-PBL complained from the amount of work and the number of hours that they have to spend each week. Also, students considered addressing the amendments of both educators and stakeholders as the biggest challenge that they have faced.

Taking everything into account, we can say that our limitations are acceptable especially because we tried to minimize them as possible.

\section{CONCLUSION AND FUTURE WORK}

To conclude, experiencing Social RE-PBL helped us to prove and validate its power and ability to support students' learning where students took exceptional responsibility and seem to have a better understanding of the concepts in class after sharing and exchanging ideas. Our teaching philosophy is based on real-time interactive learning using social networks. This interaction has the potential to help in improving students' performance in practice as students are motivated to use social networks. Moreover, we found out that the described approach has the potential to strengthen the relationship between the learners, educators and stakeholder, where the involvement of members from multi disciplines inspires, encourages, enhances students' learning and helps to create students who are motivated to achieve their targets. Also, such integration between SNSs and PBL creates opportunities for developing creative experiences in requirements engineering education. Therefore, Social RE-PBL helped students to realize and better understand the concepts that are learned during the course.

Students talked about their concerns and worries because of what they think and of what they know from their colleagues who graduated about moving from studying to working environment. They also expressed their feeling regarding presenting their work and with regard to dealing with real stakeholders. They disbelieved that they can develop solutions that meet stakeholders' needs and views. Our results demonstrated the efficiency of Social RE-PBL in reducing this gap between study and practice where students gain real-world experience and deal with real stakeholders. In future, Social RE-PBL can be applied to another module with a bigger number of students to examine its efficiency in reducing this gap between study and practice.

\section{CONFLICT OF INTEREST}

The author declares no conflict of interest.

\section{AUTHOR CONTRIBUTIONS}

The author confirms sole responsibility for the following: study conception and design, data collection, analysis and interpretation of results, manuscript preparation, and final approval of the version to be published.

\section{ACKNOWLEDGMENT}

Our work was made possible by the 'Software Requirements Engineering: Modeling, Validation \& Verification, and Evolution' project at Philadelphia University. Special thanks to colleagues in the project and to Professor Said Ghoul- the leader of the project-. We also thank stakeholders and industrial users who helped in the requirements engineering exercises and for providing helpful comments on the collected requirements.

\section{REFERENCES}

[1] P. Zave, "Classification of research efforts in requirements engineering," ACM Computing Surveys, vol. 29, no. 4, pp. 315-321, December 1997.

[2] I. Sommerville and J. Ransom, "An empirical study of industrial requirements engineering process assessment and improvement," ACM Transactions on Software Engineering and Methodology, vol. 14, no. 1, pp. 85-117, Jan 2005.

[3] O. Minor and J. Armarego, "Requirements engineering: A close look at industry needs and model curricula," in Proc. the 9th Australian Workshop on Requirements Engineering, 2004, pp. 9.1-9.10.

[4] S. Ouhbi, A. Idri, J. L. Fernández-Alemán, and A. Toval, "Requirements engineering education: a systematic mapping study," Requirements Engineering, vol. 20, no. 2, pp. 119-138, 2013

[5] P. Blumenfeld, B. J. Fishman, J. Krajcik, R. W. Marx, and E. Soloway, "Creating usable innovations in systemic reform: Scaling up technology-embedded project-based science in urban schools," Educational Psychologist, vol. 35, no. 3, pp. 149-164, 2000.

[6] W. J. Stepien and S. L. Pyke, "Designing problem-based learning units," Journal for the Education of the Gifted, vol. 20, no. 4, pp. 380-400, June 1997. 
[7] P. R. Cunha, "Teaching software engineering using project-based learning," presented at International Conference on Engineering Education and Research (ICEER), Tainan, Taiwan, February 27-28, 2005.

[8] R. P. Salas, "Teaching entrepreneurship in computer science: Lessons learned," in Proc. Frontiers in Education Conference (FIE), 2017, pp. 1-7. doi: 10.1109/FIE.2017.8190664.

[9] Z. Luciana and A. Álvaro, "A design methodology for user-centered innovation in the software development area," Journal of Systems and Software, vol. 110, pp. 155-177, Dec. 2015

[10] K. Buffardi, C. Robb, and D. Rahn, "Learning agile with tech startup software engineering projects," in Proc. the ACM Conference on Innovation and Technology in Computer Science Education ITiCSE'17, 2017, pp. 28-33.

[11] Y. He, "Description of a cloud based private social network security scheme," International Journal of Information and Education Technology, vol. 5, no. 7, pp. 532-537, 2015.

[12] B. Doğan, Ö. Demir, and E. E. Ülkü, "Applying social networks to engineering education," Special Issue: Twenty-Fifth Anniversary Special Issue of Computer Applications in Engineering Education Innovation in Engineering Education with Digital Technologies, vol 26, no. 5, June 2018

[13] S. S. Oyelere, V. Paliktzoglou, and J. Suhonen, "M-learning in Nigerian higher education: An experimental study with Edmodo," International Journal of Social Media Interactive Learning Environment, vol. 4, pp. 43-62, Jan. 2016.

[14] M. D. Roblyer, M. McDaniel, M. Webb, J. Herman, and J. V. Witty, "Findings on facebook in higher education: A comparison of college faculty and student uses and perceptions of social networking sites," The Internet and Higher Education, vol. 13, pp. 134-140, June 2010.

[15] S. Aydin, "A review of research on Facebook as an educational environment," Educational Technology Research and Development vol. 60, pp. 1093-1106, Dec. 2012.

[16] P. Kirschner and A. C. Karpinski. "Facebook and academic performance," Computer in Human Behavior, vol. 26, pp. 1237-1245, Nov. 2010.

[17] S. G. Mazman and Y. K. Usluel, "Modeling educational usage of Facebook," Computers \& Education, vol. 55, pp. 444-453, Sep. 2010.

[18] D. Carmichael and C. MacEachen, "Heuristic evaluation of the use of blackboard \& facebook groups in computing higher education,"
International Journal of Modern Education and Computer Science (IJMECS), vol. 9, pp. 1-8, June 2017.

[19] C. Lampe, D. Y. Wohn, J. Vitak, N. B. Ellison, and R. Wash, "Student use of Facebook for organizing collaborative classroom activities," International Journal of Computer-Supported Collaborative Learning, vol. 6, pp. 329-347, April 2011.

[20] N. Madhav and M. K. Joseph, "Cloud for engineering education: Learning networks for effective student engagement," in Proc. IEEE 7th Annual Computing and Communication Workshop and Conference (CCWC), 2017, pp. 1-4.

[21] Y. Huang, "Exploring the intention to use cloud services in collaboration contexts among Taiwan's private vocational students," Information Development, vol. 33, pp. 29-42, Feb. 2017.

[22] L. Qin, J. Hsu, and M. Stern, "Evaluating the usage of cloud-based collaboration services through teamwork," The Journal of Education for Business, vol. 91, pp. 227-235, April 2016.

[23] Z. A. Shana and E. Abulibdeh, "Engaging students through blogs: Using blogs to boost a course experience," International Journal of Emerging Technologies in Learning (IJET), vol. 10, no. 1, pp. 30, 2015.

[24] S. Jacques, S. Bissey, and A. Martin, "Multidisciplinary project based learning within a collaborative framework: A case study on urban drone conception," International Journal of Emerging Technologies in Learning (IJET), vol. 11, no. 12, pp. 36, 2016.

Copyright $\odot 2021$ by the authors. This is an open access article distributed under the Creative Commons Attribution License which permits unrestricted use, distribution, and reproduction in any medium, provided the original work is properly cited (CC BY 4.0).

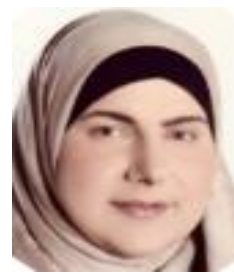

Lamis F. Al-Qora'n is an assistant professor at the Department of Software Engineering, Philadelphia University, Jordan. She holds a PhD and MSc in computer science/ software engineering from the Department of Computer Science, University of Hull, UK. She got the full PhD scholarship from Philadelphia University, Jordan and partial MSc scholarship from University of Hull, UK. She got the BSc. in computer science was from the Department of Computer Science, Yarmouk University, Jordan 